\title{
Temperamental Characteristics of Pre-School Children Who Stutter
}

\author{
Eun-Ae Lee ${ }^{1}$, Seong Hee Choi ${ }^{2}$, Chul-Hee Choi ${ }^{2}$, Kyungjae Lee ${ }^{2}$ \\ 'Jeonggwan Bareum Psychology Communication Center, Graduate School, Daegu Catholic University, Gyeongsan, Korea \\ ${ }^{2}$ Department of Audiology and Speech-Language Pathology, Daegu Catholic University, Gyeongsan, Korea
}

\author{
Received: July 14, 2020 \\ Revised: August 31, 2020 \\ Accepted: September 21, 2020 \\ Correspondence: \\ Kyungjae Lee, PhD \\ Department of Audiology and \\ Speech-Language Pathology, \\ Daegu Catholic University, \\ 13-13 Hayang-ro, Hayang-eup, \\ Gyeongsan 38430, Korea \\ Tel: +82-53-850-2543 \\ Fax: +82-53-359-6780 \\ E-mail: kjlee0119@cu.ac.kr
}

\begin{abstract}
Purpose: Stuttering is a multi-dynamic disorder and there may be various factors related to development of stuttering. Temperamental characteristics of children who stutter (CWS) may be one of those factors but there are only a few Korean empirical studies on such characteristics of pre-school CWS. The primary purpose of the current study was to determine whether there would be differences in temperamental characteristics between pre-school CWS and children who do not stutter (CWNS). In addition the correlations between stuttering and temperament were determined. Methods: A total of 28 CWS and CWNS took part in the current study; 14 male CWS [mean age: 55.1 months, standard deviation (SD): 6.4] and 14 male CWNS (mean age: 54.1 months, SD: 4.8). The participants completed temperamental and psychological measures for children, such as KoreanPersonality Rating Scale for Children, The Junior Temperament and Character Inventory 3-6, Korean Preschool Daily Stress Scale, and KiddyCAT. Results: The results of the current study showed that there was a statistically significant difference in Persistence and KiddyCAT scores between CWS and CWNS. Even though there was no significant relationship between temperament and stuttering for CWS several significant relationships were observed among temperament measure scores. Conclusion: These results suggested that temperamental characteristics may contribute to the development of stuttering partly. Accordingly multi-dimensional features should be considered in the clinical management of stuttering.
\end{abstract}

Key Words: Children, Stuttering, Temperament.

\section{INTRODUCTION}

말더듬은 선천적 요인, 환경적 요인, 발달적 요인 등의 상호작 용으로 발생하는 다면적인 장애이다(Guitar, 2014; Manning, 2010). 이러한 말더듬의 발생과 진전에 영향을 미치는 선천적인 요인 중의 하나로 기질(temperament)이 제시되었다(Anderson et al., 2003). 기질이란 생의 초기부터 보이는 개인의 특성으로 한 개인의 행동 양식과 정서적 반응을 의미하며, 사회적 상황 에 따라 반응하고 대처하는 기제이다(Rothbart \& Derryberry, 1981). 이와 관련하여 Riley \& Riley(2000)는 말더듬아동의 진 단에 관한 포괄적인 시각을 포함한 수정된 구성모델(revised component model, RCM)을 제시하였다. 수정된 구성 모델에 따르면 말더듬과 관련있다고 생각되는 요인은 크게 세 가지 구 성요소, 즉 신체적 특질, 기질적 요인, 청자의 반응이며 이러한 다면적 특성이 말더듬 발생 및 발전에 종합적으로 영향을 끼친

(c) This is an Open Access article distributed under the terms of the Creative Commons Attribution Non-Commercial License (https://creativecommons.org/licenses/by-nc/4.0) which permits unrestricted non-commercial use, distribution, and reproduction in any medium, provided the original work is properly cited.
다. 특히 기질적 요인으로는 높은 자기 기대와 과도한 민감성이 제시되었으며 대략적으로 40 60\%의 아동이 이러한 기질적 요 인을 가지고 있는 것으로 제시되었다. 이러한 기질적 특성이 관 찰되는 경우에는 임상가는 아동을 이해하는 것이 필요하며 아 동의 경험 등을 같이 이야기하는 접근법을 사용할 수 있다고 제시되었다. 즉 기질적 특성이 말더듬 발생 및 발달에 영향을 끼칠 수 있기에 이를 적절히 파악하고 임상에 효율적으로 적용 할 수 있다는 점이 강조되었다.

말더듬는 사람의 기질에 대한 연구는 다양한 방식으로 진행 되었는데 우선 여러 다양한 집단이 말더듬는 사람들이 기질적 특성에서 차이가 있다는 부정적인 고정관념을 가지고 있다고 보고되었다. 예를 들어 말더듬성인은 일반인과 비교, 민감성, 완벽주의, 불안 등과 같은 기질적인 특성에서 차이를 보이는 것 으로 인식된다(Fowlie \& Cooper, 1978; Sim, 2000; Woods \& Williams, 1971). 이러한 고정관념은 일반인뿐만 아니라 언어재 활사, 말더듬아동의 부모, 언어병리학 전공자 등 다양한 집단에 서 공유된다(Fowlie \& Cooper, 1978; Sim, 2000; Woods \& Williams, 1971). 말더듬아동의 부모는 말더듬아동이 요구가 많 
고, 걱정이 많으며, 완벽주의 특징이 있다고 생각한다(Bloodstein \& Ratner, 2008).

말더듬는 사람을 대상으로 하는 실증적 연구 역시 일부 연 구는 일반인과 비교, 기질적 차이를 보고하기도 하였으나 비일 관적인 경우도 있다. 예를 들어 말더듬성인과 일반성인을 대상 으로 불안을 살펴본 연구에서 상태 불안과 특성 불안 중 특성 불안에서 집단 간 차이가 통계적으로 유의하지 않았다(Miller $\&$ Watson, 1992). 또한 말더듬성인을 대상으로 성별에 따라 불 안에서 차이가 있는지 살펴본 연구에서 말더듬 성인여성이 말 더듬 성인남성보다 불안이 높은 편이였으나 그 차이가 통계적 으로 유의하지는 않았다(Craig, 1990). 이와 같은 연구들은 자 기보고 형식의 평가도구를 사용하였다. 더불어 자기보고 형식 이 아닌 생리적 반응 등을 통하여 기질을 살펴본 연구 역시 비 일관적인 결과를 보고하였다. 말더듬성인과 일반성인 사이에 반응성에서 차이가 나타난다고 Blood et al.(1994)은 보고하였 다. 반면 Weber \& Smith(1990)는 두 집단 사이에서 말 관련 자율신경 반응의 차이가 나타나지 않으나 말더듬성인의 경우, 말과 반응 정도 사이의 관련성을 지적하였다. 말더듬아동을 대 상으로 하는 연구는 일반적으로 부모보고를 이용한 설문지를 사용하여 연구를 진행하였으며, 이런 연구들은 말더듬아동은 일반아동에 비해 높은 활동 수준, 접근, 불안, 분노 등과 더불 어 환경에 대한 낮은 적응력과 주의집중 및 전환에 어려움 등 을 보이는 것으로 보고하였다(Anderson et al., 2003; Eggers et al., 2010; Embrechts et al., 2000; Howell et al., 2004; Johnson et al., 2010; Karrass et al., 2006; Schwenk et al., 2007). 비록 이와 같은 연구들이 말더듬아동과 일반아동의 기 질적 차이를 보고하고는 있으나 일부 연구는 참여 아동의 연령 대가 3 8세로 넓은 편이거나(Eggers et al., 2010; Karras et al., 2006), 남녀 아동을 모두 통합하여 분석하기도 하였다(Anderson et al., 2003). 이와 유사하게 학령기 말더듬아동, 청소년, 성 인 등을 대상으로 실시한 일부 국내 연구는 이들이 일반인보다 높은 불안수준을 보이며, 불안이 높을수록 의사소통태도도 부 정적이라고 보고하였다(Kim et al., 2014; Ko \& Kwon, 2010). 반면 Park(2015)은 학령전기 말더듬아동의 경우, 불안 등을 포 함하는 부정적 정서, 충동성 등을 포함하는 외향성에서는 일 반아동과 유의한 차이를 보이지 않았으나 낮은 자극 선호성 등 을 포함하는 의도적 통제에서는 유의한 차이를 보였다고 보고 하였다. 하지만 이와 같은 국내 연구 역시 해외 연구와 마찬가 지로 넓은 연령대와 이로 인한 치료 경험 여부, 성별 등이 통제 되지 못하였다는 단점이 있다. 비록 기질이 타고난 성향이기는 하지만 말더듬에 대한 오랜 경험 및 치료 경험, 성별 등에 따라 서 심리적 특성은 다른 양상을 보일 수 있기에 이러한 요인을 통제하여 말더듬아동과 일반아동을 비교하여 살펴볼 필요가
있다. 이와 관련하여 Eggers et al.(2010)은 기질이 치료 기간 및 말더듬 중증도 등과 관련성이 없다고 하였으나 참여자 중 대부 분(54/58명)이 평균 약 8.9개월의 치료를 받았으며 치료를 받지 않은 아동은 소수(4/58명)에 불과하였다. 또한 일반적으로 성에 따른 기질의 차이 역시 제시되었다(Else-Quest et al., 2006). 이 에 보다 균일한 특성을 지닌 말더듬아동과 일반아동을 대상으 로 기질적 차이를 살펴보고 이러한 기질적 특성과 말더듬 사이 의 상관관계를 살펴보는 연구는 말더듬의 다면적인 특성과 관 련된 기초 정보를 제공할 수 있을 것으로 기대된다.

이에 본 연구에서는 성별, 나이, 말더듬 지속 기간, 치료 경험 등을 통제한 학령전기 말더듬아동을 대상으로 이들의 기질을 살펴보고자 하였다. 이를 위하여 치료 경험이 없는, 말을 더듬은 지 6개월 이내의 학령전기 말더듬 남자아동과 학령전기 일반 남 자아동의 기질을 비교하였다. 또한 기질과 말더듬의 관련성을 살펴보기 위하여 다양한 기질 특성과 말더듬 사이의, 그리고 여 러 다양한 기질 특성 사이의 상관관계를 살펴보았다. 이러한 다 양한 상관관계 분석을 통하여 다양한 기질과 말더듬의 관련성 이 두 집단 사이에서 차이가 나타나는지 살펴보았다. 전술한 바 와 같이 보다 균일한 집단을 대상으로 기질적 특성 차이를 살펴 보고 기질적 특성과 말더듬 사이의 상관관계 측정을 통하여 효 율적인 말더듬 평가와 종합적인 중재에 기여를 하고자 하였다.

\section{MATERIALS AND METHODS}

\section{연구 대상}

본 연구에는 부산, 울산, 경남 등의 지역에서 거주하고 있는 학령전기 말더듬 남자아동 14명[평균연령: 55.1개월, standard deviation $(\mathrm{SD})=6.4]$, 이들과 연령이 일치된 학령전기 일반 남 자아동 14 명(평균연령: 54.1 개월, $\mathrm{SD}=4.8$ ), 총 28 명이 참여하 였다. 말더듬아동의 선정기준은 다음과 같다. 1) 부모, 유치원 혹은 어린이집 교사가 말더듬을 의심한 아동, 2) 언어재활사 국 가자격증을 소지한 언어치료사가 파라다이스-유창성 검 사-II(Paradise-Fluency Assessment-II, P-FA-II) (Sim et al., 2010)를 실시하여 말더듬으로 진단한 아동, 3) 부모 보고에 따 르면 말더듬 시작시기가 6개월 이내인 아동, 4) 말더듬 관련 언 어치료 경험이 없는 아동이었다. 본 연구에 참여한 말더듬아동 의 중증도를 P-FA-II로 측정한 결과, 약함 2 명, 중간 10 명, 심 함 2명이었다. 일반아동의 선정기준은 다음과 같다. 1) 부모, 유 치원 혹은 어린이집 교사가 말더듬을 의심하지 않는 아동, 2) 언어재활사 국가자격증을 소지한 언어재활사가 아동과의 상호 작용 시, 말더듬과 관련된 비유창성, 부수행동 및 감정과 태도 등이 관찰되지 않은 아동이었다.

모든 참여 아동은 취학 전 아동의 수용언어 및 표현언어 발달 
척도(Preschool Receptive-Expressive Language Scale) (Kim et al., 2003) 결과, 생활 연령과 비교 6개월 이내의 지체를 보이 는 정상 범위의 언어발달 수준을 보였다. 또한 부모보고에 따르 면 시각, 청각, 인지, 행동 등의 영역에서 다른 동반장애가 없는 아동이었다.

\section{연구 도구}

본 연구에서는 참여 아동의 다양한 기질과 심리적 특성을 살펴보기 위하여 한국아동인성평정 척도(Korean-Personality Rating Scale for Children, KPRC) (Kim et, al., 2006), 유아용 기질 및 성격 검사(The Junior Temperament and Character Inventory, JTCI 3 6) (Min et, al., 2007), 유아용 일상 스트레 스 척도(Korean Preschool Daily Stress Scale, KPDSS) (Yeom, 1998)를 실시하였다.

$\mathrm{KPRC}$ 는 보호자가 아동에 대해 작성하는 설문지 형태의 검 사로 아동의 기질을 다차원적으로 평가한다. $\mathrm{KPRC}$ 는 3 개의 타당도 척도(검사-재검사 척도, 허구 척도, 빈도 척도), 한 개의 자아탄력성 척도(ego resilience), 10 개의 임상 척도로 구성된 다. 10 개의 임상 척도는 언어발달(verbal development), 운동 발달(performance development), 불안(anxiety), 우울(depression), 신체화(somatozation), 비행(delinquency), 과잉행동 (hyperactivity), 가족관계(family interaction), 사회관계(social interaction), 정신증(psychoticism) 등이다.

JTCI 3 6 (Min et al., 2007)은 심리생물학 인성 모델에 기 반하여 유아의 기질과 성격을 측정하기 위해 개발된 기질 및 성격 검사도구이다. JTCI 3 6은 기질을 측정하는 네 개의 척 도(자극추구, 위험회피, 사회적 민감성, 인내력)와 성격을 측정 하는 세 개의 척도(자율성, 연대감, 자기초월), 총 7 개의 기본 척 도로 이루어져 있다. 말더듬아동은 새로운 환경에 대해 예민함 과 민감한 기질을 가지고 있으며, 완벽주의 성향 역시 말더듬과 관련이 있는 것으로 제시되었다(Bloodstein \& Ratner, 2008; Riley \& Riley, 2000). 이에 본 연구에서는 기질을 측정하는 위 네 가지 척도 중 말더듬과 관련 있다고 여겨지는 기질적 특성인 사회적 민감성과 인내력, 두 가지 척도를 측정하였다. 사회적 민 감성(reward dependence)이란 사회 보상 신호와 상대방의 감정 에 대해 민감하게 반응하는 성향이며, 정서적 감수성, 애착도, 의존성 등 총 세 가지 하위 영역으로 구성된다. 인내력(persistence)은 지속적인 강화가 없어도 한 번 보상된 행동을 일정한 시간 동안 꾸준히 지속하려는 성향이며 완벽주의와 지속력 등 총 두 가지 하위 영역으로 구성된다. JCTI 3 6역시 설문지 형 태의 검사이며 보호자가 작성한다.

KPDSS (Yeom, 1998)는 만 3 6세 유아의 일상적 스트레스 를 측정하는 평가도구로 평가자가 직접 아동을 대상으로 실시
한다. $\mathrm{KPDSS}$ 는 비난/공격적 상황, 불안/좌절감 경험, 자존감 상함 등의 3 가지 종류, 총 23 상황을 제시하고 아동이 이러한 상황을 경험하는지, 그리고 그러한 상황에서 느끼는 스트레스 정도를 크기가 다른 동그라미를 제시하여 선택하게 한다. 동그 라미 크기에 따라 1 3점을 부여하며, 각 스트레스 상황에 따른 점수의 총합을 측정한다.

본 연구에서는 또한 참여자의 의사소통태도를 살펴보기 위 해 유아용 의사소통태도 검사인 KiddyCAT (Lee et al., 2013; Vanryckeghem et al., 2005)을 실시하였다. KiddyCAT은 12문 항으로 구성되어 있으며 3 6세 아동의 의사소통태도를 평가 한다. 또한 말더듬아동의 전반적인 비유창성 정도를 측정하기 위하여 P-FA-II (Sim et al., 2010)의 필수과제를 실시하였다.

\section{연구 절차}

본 연구의 실험과정은 다음과 같다. 모든 실험은 조용한 장소 에서 연구자와 아동(혹은 부모)이 일대일로 진행하였다. 우선 본 연구 목적 및 절차 등에 대해서 보호자에게 설명한 후 대구가톨 릭대학교 생명윤리심의위원회가 승인한 연구 참여 동의서 (CUIRB-2018-0014)에 서명을 하게 하였다. 이후 연구자는 아동 을 대상으로 언어평가와 말더듬 평가를 실시하였으며, 아동의 어 머니는 KPRC와 JTCI 3 6를 무순으로 작성하였다. 말더듬 평 가는 추후 분석을 위하여 비디오 녹화를 하였다. 또한 연구자는 아동을 대상으로 KiddyCAT과 KPDSS를 무순으로 실시하였다.

\section{통계 분석}

우선 $\mathrm{KPRC}$ 의 경우 10 개의 임상 척도 중 기질적 특성을 측 정하는 척도가 아닌 언어발달과 운동발달을 제외한 여덟 개의 임상 척도 점수를 산출하였다. 이와 더불어 자아탄력성 척도 점수 역시 산출하였다. 대상자의 설문지는 온라인 분석되어 각 척도별 표준점수(평균이 50점인 $\mathrm{T}$ 점수)가 제공되었다. 자아탄 력성의 경우 $\mathrm{T}$ 점수가 높을수록 탄력성이 높다라는 것을 의미 하며 점수가 낮을수록 스트레스 대처에 필요한 심리적 자원이 부족함을 의미한다. 그 외의 임상 척도에서는 $\mathrm{T}$ 점수가 높을수 록 부정적으로 해석한다. JTCI 3 6의 경우, 전술한 바와 같이 사회적 민감성과 인내력 두 가지 척도와 각 척도의 하위 영역을 분석하였다. 부모는 라이케르트 척도로 응답하였으며, 점수가 높을수록 해당 특성이 높은 것으로 분석된다. KPDSS의 경우, 세 가지 상황의 총점을 계산하였으며 높은 점수는 높은 스트레 스 정도를 나타낸다. KiddyCAT의 경우, 말더듬는 아동이 답할 것으로 예상되는 방식으로 대답한 항목의 숫자를 점수화하였 으며, 이에 점수가 높을수록 부정적인 의사소통태도를 나타낸 다. P-FA-II 필수과제의 경우, 정상적 비유창성 점수와 비정상 적 비유창성 점수의 총합인 총 비유창성 점수를 산출하였다. 
또한 본 연구에서는 전체 말더듬아동 20\%인 3명을 무작위 로 선별하여 P-FA-II 분석에 대한 평가자 간 분석 신뢰도를 측 정하였다. 본 연구의 연구자와 1 급 언어재활사 자격증을 소지하 고 말더듬 평가와 치료 경력이 3년 이상인 독립된 언어재활사의 $\mathrm{P}-\mathrm{FA}-\mathrm{II}$ 필수과제 점수를 대상으로 분석한 결과, $\mathrm{r}=0.98$ ( $p<$ 0.001)로 높은 신뢰도를 보였다.

본 연구의 통계분석 방법은 다음과 같다. 우선 말더듬아동과 일반아동이 여러 평가도구 점수에서 차이를 보이는지 살펴보 기 위하여 독립표본 $t$-test를 실시하였다. SPSS 윈도우용 프로 그램(version 19, IBM Corp., Armonk, NY, USA)을 사용하였 으며 유의수준은 0.05 로 하였다. 더불어 집단 간 차이의 크기 를 살펴보기 위하여 효과크기를 Cohen's d를 사용하여 살펴보 았다. 또한 말더듬아동의 기질 및 심리 특성이 말더듬과 상관 이 있는지 알아보기 위해 $\mathrm{P}-\mathrm{FA}-\mathrm{II}$ 의 필수과제 점수와 기질 및 심리 검사 점수, KiddyCAT 점수 사이의 상관관계를 Pearson $r$ 을 이용하여 살펴보았다.

\section{RESULTS}

\section{한국아동인성평정 척도(KPRC) 결과}

본 연구에 참여한 학령전기 말더듬아동과 일반아동의 $\mathrm{KPRC}$ 자아탄력성 척도와 여덟 개 임상 척도 평균과 표준편차, 독립 $t$ 검정 결과는 Table 1 에 제시되었다. 자아탄력성 척도 결과, 말 더듬아동의 평균점수는 66.71(SD = 13.61), 일반아동의 평균점 수는 70.64(SD = 14.16)였으며, 집단 간 차이는 통계적으로 유 의하지 않았다 $[t(26)=-0.749, p=0.461$, Cohen's $d=0.28]$. 또 한 말더듬아동과 일반아동 모두 여덟 개 임상 척도에서 평균 40 50점 초반을 기록하였으며, 모든 척도에서 학령전기 일반아 동과 말더듬아동의 차이는 통계적으로 유의하지 않았다 $(p>$ 0.05). 비록 통계적으로 유의한 차이를 보이지는 않았으나 불안 에서 말더듬아동과 일반아동의 차이 크기는 중간 정도(Cohen's $\mathrm{d}=0.70)$ 였다. 이어서 정신증(Cohen's $\mathrm{d}=0.46)$, 가족관계 $\left(\mathrm{Co}^{-}\right.$ hen's $d=0.45)$, 사회관계(Cohen's $d=0.35)$, 자아탄력성 $\left(\mathrm{Co}^{-}\right.$ hen's d = 0.28), 과잉행동(Cohen's d = 0.27), 우울(Cohen's $d=$ $0.21)$ 등의 순으로 효과크기를 보였으나 그 차이는 작은 편이었 다(Cohen, 1988).

\section{유아용 기질 및 성격 검사(JTCl 3 6) 결과}

학령전기 말더듬아동의 인내력 척도의 평균은 23.79점(SD: $3.60)$, 학령전기 일반아동은 평균 21.36점(SD: 1.74)이었다(Table 2). 이러한 점수 차이는 통계적으로 유의하였으며 효과크기 는 큰 편이었다 $[t(26)=2.274, p=0.031$, Cohen's $\mathrm{d}=0.86]$. 반 면 인내력 척도의 두 하위 영역인 완벽주의와 지속력은 집단 간 차이가 통계적으로 유의하지 않았으며 완벽주의의 효과크

Table 1. Korean-Personality Rating Scale for Children mean scores (standard deviation) and $t$-test results

\begin{tabular}{lcccc}
\hline \multicolumn{1}{c}{ Category } & Children who stutter & Children who do not stutter & $t$ & -0.749 \\
\hline Ego resilience & $66.71(13.61)$ & $70.64(14.16)$ & 1.840 & 0.28 \\
Anxiety & $48.71(9.92)$ & $42.14(8.95)$ & 0.551 & 0.70 \\
Depression & $47.93(13.62)$ & $45.14(13.13)$ & 0.136 & 0.21 \\
Somatozation & $43.34(10.39)$ & $42.86(11.85)$ & 0.507 & 0.04 \\
Delinquency & $47.57(10.17)$ & $45.79(8.41)$ & 0.726 & 0.19 \\
Hyperactivity & $50.36(7.51)$ & $47.93(10.01)$ & 1.200 & 0.27 \\
Family interaction & $51.71(15.45)$ & $45.50(11.70)$ & 0.920 & 0.45 \\
Social interaction & $47.64(12.97)$ & $43.71(9.32)$ & 1.209 & 0.35 \\
Psychoticism & $49.07(11.58)$ & $43.64(12.18)$ & 0.46 \\
\hline
\end{tabular}

Table 2. The Junior Temperament and Character Inventory 3-6 mean scores (standard deviation) and $t$-test results

\begin{tabular}{|c|c|c|c|c|}
\hline Category & Children who stutter & Children who do not stutter & $t$ & Cohen's d \\
\hline Persistence & $23.79(3.60)$ & $21.36(1.74)$ & $2.274^{*}$ & 0.86 \\
\hline \multicolumn{5}{|l|}{ Subscales } \\
\hline Perfectionism & $13.93(2.80)$ & $12.14(1.88)$ & 2.003 & 0.75 \\
\hline Vitality & $9.86(2.66)$ & $9.21(0.89)$ & 0.858 & 0.32 \\
\hline Reward dependence & $26.00(6.35)$ & $26.07(5.53)$ & -0.032 & 0.01 \\
\hline \multicolumn{5}{|l|}{ Subscales } \\
\hline Sentimentality & $9.64(2.21)$ & $9.21(1.93)$ & 0.547 & 0.21 \\
\hline Attachment & $8.07(3.03)$ & $8.21(2.91)$ & -0.127 & 0.05 \\
\hline Dependence & $8.29(2.76)$ & $8.64(2.56)$ & -0.355 & 0.13 \\
\hline
\end{tabular}
${ }^{*} p<0.05$ 
기는 중간(Cohen's $\mathrm{d}=0.75)$, 지속력의 효과크기는 작은 편 $\left(\mathrm{Co}^{-}\right.$ hen's d = 0.32)이었다. 또한 JTCI 3 6의 사회적 민감성 척도 및 해당 척도의 세 가지 하위 영역인 정서적 감수성, 애착도, 의존 성 모두 집단 간 차이가 통계적으로 유의하지 않았으며 $(p>$ 0.05), 효과크기는 모두 작은 편이었다.

\section{유아용 일상 스트레스 척도(KPDSS) 결과}

학령전기 말더듬아동의 KPDSS 평균은 44.71점(SD: 15.50), 일반아동의 평균 44.50점(SD: 13.84)이었다(Table 3). 집단 간 차이는 통계적으로 유의하지 않았으며 효과크기는 매우 작았 다 $[t(26)=-0.332, p=0.750$, Cohen's $\mathrm{d}=0.01]$.

\section{의사소통태도검사(KiddyCAT) 결과}

학령전기 말더듬아동의 평균점수는 4.21점 $(\mathrm{SD}=2.97)$ 이며 학령전기 일반아동의 평균점수는 1.07 점 $(\mathrm{SD}=1.33)$ 이었다 (Table 3). 이러한 점수 차이는 통계적으로 유의하였으며 효과 크기는 매우 컸다 $[t(26)=3.619, p=0.001$, Cohen's $\mathrm{d}=1.36]$.

\section{기질과 말더듬 점수 상관관계}

연구에 참여한 학령전기 말더듬아동과 일반아동의 기질 평 가도구 점수와 $\mathrm{P}-\mathrm{FA}-\mathrm{II}$ 필수과제 점수 사이에서 관찰된 유의 한 상관관계는 Table 4 와 같다. 우선 말더듬아동의 경우, PFA-II 필수과제 총점과 유의한 상관관계를 보인 것은 KiddyCAT 점수였다. P-FA-II 필수과제 총점과 KiddyCAT 점수 사 이에는 유의한 정적 상관관계가 관찰되었다 $(\mathrm{r}=0.593, \mathrm{p}=$ 0.025). P-FA-II는 그 밖의 다른 기질 및 심리 특성과 유의한 상관관계를 보이지 않았다.

\section{기질특성 사이의 상관관계}

여러 기질적 특성 사이에는 유의한 상관관계가 관찰되었으 며, 일부 유의한 상관관계는 두 집단에서 모두 관찰되었다. 예 를 들어 말더듬아동과 일반아동 모두 자아탄력성은 불안, 우 울, 비행, 가족관계, 사회관계, 정신증 등과 부적 상관관계를 보 였다. 즉 두 집단 모두 자아탄력성이 높을수록 불안, 우울, 정신 증, 비행, 가족관계 및 사회관계 문제 등은 적다는 점을 나타낸 다. 또한 불안은 우울, 과잉행동, 사회관계, 정신증 등과 정적 상

Table 3. KPDSS and KiddyCAT mean scores (standard deviation) and $t$-test results

\begin{tabular}{lcccc}
\hline & $\begin{array}{c}\text { Children who } \\
\text { stutter }\end{array}$ & $\begin{array}{c}\text { Children who } \\
\text { do not stutter }\end{array}$ & $t$ & Cohen's d \\
\hline KPDSS & $44.71(15.50)$ & $44.50(13.84)$ & -0.322 & 0.01 \\
KiddyCAT & $4.21(2.97)$ & $1.07(1.33)$ & $3.619 *$ & 1.36 \\
\hline${ }^{*} p<0.05$. KPDSS: Korean Preschool Daily Stress Scale
\end{tabular}

관관계를 보였는데 이는 두 집단 모두 불안이 높을수록 우울, 과잉행동, 정신증, 사회관계 문제 등이 높다는 점을 나타낸다.

더불어 각 집단별로 다른 상관관계가 관찰되기도 하였는데, 많은 경우 말더듬아동에서 유의한 상관관계가 더 많이 관찰되 었다. 대표적으로 말더듬아동의 경우 자아탄력성은 사회적 민 감성, 정서적 감수성, 의존성 등과 부적 상관관계를 보인 반면 일반아동은 신체화와 부적 상관관계를 보였다. 즉 위에서 언급 된 공통된 상관관계와 더불어 말더듬아동의 경우, 자아탄력성 이 높을수록 사회적 민감성, 정서적 감수성, 의존성 등이 낮은 반면 일반아동은 신체화 정도가 낮다는 점을 나타낸다. 더불어 불안의 경우 말더듬아동은 가족관계, 사회적 민감성, 의존성, 스트레스 등과 정적 상관계를 보인 반면 일반아동은 신체화와 정적 상관관계를 보였다. 즉 말더듬아동은 불안이 높을수록 가족관계, 사회적 민감성, 의존성, 스트레스 등이 높은 반면 일 반아동은 신체화 정도가 높다는 점을 나타낸다.

\section{DISCUSSIONS}

본 연구는 학령전기 말더듬아동의 기질 특성을 일반아동과 비교하였으며 주요 결과는 다음과 같다. 우선 말더듬 치료 경험 이 없는 학령전기 말더듬 남자아동과 일반 남자아동을 비교한 결과, 일부 기질에서만 통계적으로 유의한 차이가 나타났다. 더 불어 여러 기질 사이에는 통계적으로 유의한 상관관계가 관찰 되었으나 말더듬과 유의한 상관관계를 보이는 기질은 없었다.

이와 같은 결과는 우선 기질이 말더듬 발생과 발달에 관련이 있다는 점을 제한적으로 시사한다. 본 연구 결과, 통계적으로 유의한 차이가 나타난 기질은 인내력이었으며, 말더듬아동이 일반아동보다 높은 인내력 성향을 보였다. 인내력은 전술한 바 와 같이 지속적인 강화가 없어도 한 번 보상된 행동을 일정한 시간 동안 꾸준히 지속하려는 성향이며 완벽주의의 지속력, 두 가지 하위 영역으로 구성되어 있다. 본 연구에 참여한 학령전기 말더듬아동의 경우, 인내력의 두 하위 영역인 완벽주의와 지속 력에서는 일반아동과 비교, 통계적으로 유의한 차이가 없었으 나 완벽주의의 경우, 효과크기가 중간 이상 $($ Cohen's $\mathrm{d}=0.75$ ) 이었다(Cohen, 1988; Sawilowsky, 2009). 이러한 결과는 본 연 구에 참여한 학령전기 말더듬아동은 일반아동과 비교, 통계적 으로 유의하게 다른 정도이지는 않지만 그럼에도 불구하고 높 은 완벽주의 성향을 보이며, 이로 인하여 인내력에서도 유의한 차이를 보였다는 점을 시사한다. 이와 관련하여 환경의 변화가 말더듬과 관련이 있을 것으로 제시되었는데(Guitar, 2014), 반면 에 아동 환경의 변화가 말더듬의 직접적인 원인이라기보다는 이러한 변화에 대한 아동의 적응력 부족이 원인이라는 점 역시 지적되었다. 예를 들어 Bloodstein \& Ratner(2008)는 말더듬아 
Table 4. Significant relationships for children who stutter and children who do not stutter $(p<0.05)$

\begin{tabular}{|c|c|c|}
\hline & Children who stutter & Children who do not stutter \\
\hline Ego resilience & $\begin{array}{l}\text { Depression }(r=-0.789) \\
\text { Reward dependence }(r=-0.767) \\
\text { Sentimentality }(r=-0.753) \\
\text { Psychoticism }(r=-0.719) \\
\text { Perfectionism }(r=-0.701) \\
\text { Social interaction }(r=-0.696) \\
\text { Delinquency }(r=-0.603) \\
\text { Family interaction }(r=-0.590) \\
\text { Anxiety }(r=-0.566) \\
\text { Dependence }(r=-0.535)\end{array}$ & $\begin{array}{l}\text { Depression }(r=-0.926) \\
\text { Social interaction }(r=-0.913) \\
\text { Psychoticism }(r=-0.856) \\
\text { Delinquency }(r=-0.831) \\
\text { Somatozation }(r=-0.687) \\
\text { Anxiety }(r=-0.680) \\
\text { Family interaction }(r=-0.568)\end{array}$ \\
\hline Anxiety & $\begin{array}{l}\text { Psychoticism }(r=0.801) \\
\text { KPDSS }(r=0.775) \\
\text { Family interaction }(r=0.749) \\
\text { Depression }(r=0.730) \\
\text { Social interaction }(r=0.666) \\
\text { Dependence }(r=0.611) \\
\text { Reward dependence }(r=0.575) \\
\text { Hyperactivity }(r=0.558)\end{array}$ & $\begin{array}{l}\text { Somatozation }(r=0.752) \\
\text { Depression }(r=0.750) \\
\text { Social interaction }(r=0.741) \\
\text { Psychoticism }(r=0.738) \\
\text { Hyperactivity }(r=0.613)\end{array}$ \\
\hline Depression & $\begin{array}{l}\text { Social interaction }(r=0.866) \\
\text { Reward dependence }(r=0.730) \\
\text { Family interaction }(r=0.692) \\
\text { Sentimentality }(r=0.688) \\
\text { Psychoticism }(r=0.680) \\
\text { KPDSS }(r=0.585) \\
\text { Dependence }(r=0.540)\end{array}$ & $\begin{array}{l}\text { Psychoticism }(\mathrm{r}=0.926) \\
\text { Social interaction }(\mathrm{r}=0.917) \\
\text { Somatozation }(\mathrm{r}=0.818) \\
\text { Delinquency }(\mathrm{r}=0.730) \\
\text { Family interaction }(\mathrm{r}=0.579)\end{array}$ \\
\hline Somatozation & $\begin{array}{l}\text { Family interaction }(r=0.694) \\
\text { Psychoticism }(r=0.668) \\
\text { Reward dependence }(r=0.616) \\
\text { Social interaction }(r=0.583) \\
\text { Sentimentality }(r=0.569)\end{array}$ & $\begin{array}{l}\text { Psychoticism }(r=0.876) \\
\text { Social interaction }(r=0.824) \\
\text { Family interaction }(r=0.668)\end{array}$ \\
\hline Delinquency & Psychoticism $(r=0.694)$ & $\begin{array}{l}\text { Social interaction }(\mathrm{r}=0.769) \\
\text { Psychoticism }(\mathrm{r}=0.682)\end{array}$ \\
\hline Family interaction & $\begin{array}{l}\text { Reward dependence }(r=0.734) \\
\text { Dependence }(r=0.717) \\
\text { Sentimentality }(r=0.660)\end{array}$ & $\begin{array}{l}\text { Social interaction }(r=0.730) \\
\text { Vitality }(r=0.593) \\
\text { Psychoticism }(r=0.570)\end{array}$ \\
\hline Social interaction & $\begin{array}{l}\text { Psychoticism }(r=0.659) \\
\text { Reward dependence }(r=0.659) \\
\text { Sentimentality }(r=0.583) \\
\text { Dependence }(r=0.569)\end{array}$ & Psychoticism $(r=0.919)$ \\
\hline Psychoticism & $\begin{array}{l}\text { Dependence }(r=0.789) \\
\text { Reward dependence }(r=0.732) \\
\text { Sentimentality }(r=0.615) \\
\text { KPDSS }(r=0.594)\end{array}$ & \\
\hline Persistence & $\begin{array}{l}\text { Perfectionism }(r=0.680) \\
\text { Vitality }(r=0.648)\end{array}$ & Perfectionism $(\mathrm{r}=0.881)$ \\
\hline Perfectionism & $\begin{array}{l}\text { Sentimentality }(r=0.720) \\
\text { Reward dependence }(r=0.615) \\
\text { Attachment }(r=0.577)\end{array}$ & \\
\hline Reward dependence & $\begin{array}{l}\text { Sentimentality }(r=0.909) \\
\text { Attachment }(r=0.786) \\
\text { Dependence }(r=0.677)\end{array}$ & $\begin{array}{l}\text { Sentimentality }(r=0.845) \\
\text { Dependence }(r=0.703) \\
\text { Attachment }(r=0.655)\end{array}$ \\
\hline $\begin{array}{l}\text { Attachment } \\
\text { Sentimentality } \\
\text { Paradise-Fluency Assessment-II }\end{array}$ & $\begin{array}{l}\text { Attachment }(r=0.765) \\
\text { KiddyCAT }(r=0.593)\end{array}$ & Sentimentality $(r=0.604)$ \\
\hline
\end{tabular}

KPDSS: Korean Preschool Daily Stress Scale 
동이 일반아동과 비교, 적응능력이 정상 범위이기는 하지만 낮 은 경향을 보인다고 제시하였다. 이러한 지적들과 유사하게 본 연구의 말더듬아동 참여자는 상대적으로 높은 완벽주의, 그리 고 이에 기반하여 높은 인내력을 보였으며, 말더듬아동이 일반 아동과 비교, 자아탄력성으로 측정된 적응능력에서 낮은 점수 를 보였으나 그 차이가 통계적으로 유의하지 않았다. 또한 이러 한 특성은 탈출행동 습득과 관련된 행동주의적 설명과 관련 있 을 수 있다. 행동주의적 설명은 탈출행동 등의 습득을 적절히 설명하는 것으로 알려져 있는데(Manning, 2010), 이에 따르면, 과거 말더듬 종료와 관련 있던 특정 행동을 말더듬아동은 지속 적으로 사용할 수 있으며, 그 결과, 탈출행동이 나타난다는 것이 다. 더불어 본 연구결과, 일반아동과는 달리 말더듬아동의 경우, 완벽주의 성향과 대처능력 사이에는 부적 상관관계가 관찰되었 는데 이러한 부적 상관관계가 이와 같은 해석을 가능하게 한다. 다만 인내력과 적응능력 사이에는 유의한 상관관계가 관찰되지 않았기에 이러한 해석은 제한적일 수 있다.

더불어 본 연구에 참여한 학령전기 말더듬아동의 경우, 말더 듬과 직접적인 상관관계를 보인 기질적 특성이 없었기에 기질과 말더듬의 보다 직접적인 관계에 대한 해석에서는 주의가 필요하 다. 본 연구에서는 말더듬 중증도를 나타낼 수 있는 P-FA-II 필 수과제 총점과 의사소통태도를 나타내는 KiddyCAT 점수가 다 양한 기질 척도와 상관관계가 있는지 살펴보았다. 연구결과, $\mathrm{P}-$ FA-II 필수과제 총점과 KiddyCAT 사이에 유의한 정적 상관관 계가 관찰되었을 뿐 다른 기질과 말더듬과 관련된 위 두 척도 와 유의한 상관관계는 관찰되지 않았다. 성인의 경우, 겉으로 드 러나는 말더듬 중증도와 의사소통태도와 같은 내적 특성 사이 의 정적 상관관계에 대해서는 비일관적인 결과가 보고되었으나 일반적으로는 크게 관련성이 없는 것으로 여겨진다. 하지만 여 러 국내 연구 결과, 본 연구와 마찬가지로 학령전기 말더듬아동 의 경우에는 겉으로 드러나는 말더듬 중증도와 의사소통태도 사이에 관련성이 제시되었다(Lee et al., 2013). 즉, 학령전기 말 더듬아동의 경우, 심하게 더듬을수록 자신의 말더듬 문제를 인 식하고 이에 대해 부정적인 태도 등을 보일 수 있다는 것이다.

비록 개별 기질 특성과 말더듬 특성 사이에는 선형적인 상관 관계가 관찰되지 않았으나 추후 이와 관련된 보다 세밀한 연구 가 필요하다. 위 Table 4에서도 제시하였듯이 본 연구에 참여한 말더듬아동과 일반아동의 여러 기질 특성 사이에는 유의한 상 관관계가 다수 관찰되었다. 특히 이러한 유의한 상관관계 중에 서는 불안과 우울 사이의 정적 상관관계와 같이 두 집단에서 공통적으로 관찰되는 것도 있었으나 다른 양상을 나타내는 것 도 있었다. 예를 들어 일반아동의 경우, 신체화 척도는 자아탄 력성과는 부적 상관관계를, 불안 및 우울 등과는 정적 상관관 계를 보였으나 이러한 상관관계가 말더듬아동에게서는 관찰되
지 않았다. 신체화 척도는 심리적인 문제를 신체 증상으로 나타 내는 신체화의 경향을 측정하며, 이러한 척도의 상승은 신체적 으로 취약한 성향과 때로는 신체 증상을 통하여 책임감을 회 피하고 불편한 상황으로부터 도피하는 특성을 나타내기도 한 다. 이에 위와 같은 상관관계는 일반아동은 높은 불안 및 우울 등을 신체적인 특성으로 나타내지만, 적응력이 좋을수록 신체 적인 특성으로 나타내는 정도는 적을 것이라는 점을 나타낸다. 또한 일반아동과는 달리 말더듬아동은 자아탄력성, 불안, 우 울, 가족관계, 사회관계 등이 인내력 혹은 민감성 등과 유의한 상관관계를 보였으며 불안과 스트레스 사이에도 유의한 상관 관계를 보였다. 즉 이러한 결과는 말더듬아동이 일반아동과는 다른 대응 전략을 보일 수 있으며, 이러한 대응 전략은 여러 기 질 특성의 역동적 관계에 근거할 수 있다는 점을 시사한다. 이 에 추후 연구에서는 보다 다양한 기질 특성을 이용하여 이러 한 기질 특성이 말더듬 중증도뿐 아니라 다양한 대응전략 등과 어떠한 관련성이 있는지 살펴볼 수 있을 것이다.

본 연구의 제한점과 후속 연구에 대한 제안은 다음과 같다. 본 연구는 말을 더듬은 지 6개월 이내의, 치료 경험이 없는 남자 아동을 대상으로 하였기에 연구결과의 일반화에 어려움이 따를 수 있다. 이에 기질이 성별에 따라 차이가 나타나는지, 그리고 기 질이 자연회복 및 치료 변화에 영향을 주는지를 후속 연구에서 는 살펴볼 수 있을 것이다. 또한 말더듬아동의 중증도는 제한적 이었기에 보다 다양한 중증도를 보이는 아동을 대상으로 말더 듬아동의 기질 및 심리 특성을 후속연구에서는 살펴볼 수 있을 것이다. 비록 기질이 타고난 성향이기는 하지만 말더듬아동의 경우, 여러 심리적 특성과 말더듬중증도와의 관련성이 제시되 었기에 이러한 중증도의 다양화가 후속 연구에서는 필수적일 것이다. 더불어 본 연구에서는 각 집단별 14 명씩 총 28 명의 아 동이 참여하였으나 후속 연구에서는 참여자 수를 확대하는 것 이 필요할 것이다. 본 연구에서는 여러 영역에서의 효과크기는 중간 정도였으나 통계적으로 유의한 차이가 나타나지 않은 결 과가 제시되었다. 후속 연구에서는 참여자 수의 확대를 통하여 보다 민감하게 집단 간 차이를 살펴볼 수 있을 것이다.

본 연구는 학령전기 말더듬아동을 대상으로 이들이 보이는 기질 및 심리 특성을 일반아동과 비교하였다. 본 연구에 참여한 말더듬아동은 일반아동과 비교, 일부 기질에서 유의한 차이를 보였으며, 여러 기질의 상관관계 양상이 집단 사이에서 차이가 나타났다. 이러한 결과는 말더듬아동의 말더듬 발생과 적응행동 에 여러 기질적 특성이 역동적으로 영향을 줄 수 있다는 점을 시사한다. 이에 보다 효율적인 말더듬치료를 위해서는 이와 같은 다양한 측면을 고려한 종합적인 중재를 제공하여야 할 것이다.

중심 단어 : 아동·말더듬·기질. 


\section{Ethical Statement}

The study was approved by the Institutional Review Board of Daegu Catholic University (CUIRB-2018-0014).

\section{Acknowledgments}

N/A

\section{Declaration of Conflicting Interests}

There are no conflict of interests.

Funding

N/A

\section{Author Contributions}

E. L. and K. L. designed and performed experiments, analyzed data, and wrote the paper; K. L., S. C., and C. C. provided statistical analysis and critical revision; Also, the authors discussed the results together and implications and commented on the manuscript at each stage.

\section{ORCID iDs}

Eun-Ae Lee

https://orcid.org/0000-0002-4174-8328

Kyungjae Lee

\section{REFERENCES}

Anderson, J. D., Pellowski, M. W., Conture, E. G., \& Kelly, E. M. (2003). Temperamental characteristics of young children who stutter. Journal of Speech, Language, and Hearing Research, 46(5), 1221-1233.

Blood, G. W., Blood, I. M., Bennett, S., Simpson, K. C., \& Susman, E. J. (1994). Subjective anxiety measurements and cortisol responses in adults who stutter. Journal of Speech and Hearing Research, 37(4), 760768.

Bloodstein, O. \& Ratner, N. B. (2008). A Handbook on Stuttering. (6th ed.). Clifton Park, NY: Delmar Learning.

Cohen, J. (1988). Statistical Power Analysis for the Behavioral Sciences. (2nd ed.). Hillsdale, NJ: Lawrence Erlbaum Associates.

Craig, A. (1990). An investigation into the relationship between anxiety and stuttering. The Journal of Speech and Hearing Disorders, 55(2), 290-294.

Eggers, K., De Nil, L. F., \& Van den Bergh, B. R. (2010). Temperament dimensions in stuttering and typically developing children. Journal of Fluency Disorders, 35(4), 355-372.

Else-Quest, N. M., Hyde, J. S., Goldsmith, H. H., \& Van Hulle, C. A. (2006). Gender differences in temperament: A meta-analysis. Psychological Bulletin, 132(1), 33-72.

Embrechts, M., Ebben, H., Franke, P., \& van de Poel, C. (2000). Proceedings from the 3rd World Congress on fluency disorders: theory, research, treatment, and self-help: Temperament: A Comparison between Children who Stutter and Children who do not Stutter. Nijmegen, The Netherlands: University of Nijmegen Press.

Fowlie, G. M. \& Cooper, E. B. (1978). Traits attributed to stuttering and nonstuttering children by their mothers. Journal of Fluency Disorders, 3, 233-246.

Guitar, B. (2014). Stuttering: An Integrated Approach to its Nature and Treatment. (4th ed.). Baltimore, MD: Lippincott Williams \& Wilkins.

Howell, P., Davis, S., Patel, H., Cuniffe, P., Downing-Wilson, D., Au-Yeung, J., et al. (2004). Proceedings from the 4th World Congress on Fluency Disorders: Fluency Development and Temperament in Fluent Children and Children who Stutter. Montreal, Canada: IFA.

Johnson, K. N., Walden, T. A., Conture, E. G., \& Karrass, J. (2010). Sponta-

neous regulation of emotions in preschool children who stutter: Preliminary findings. Journal of Speech, Language, and Hearing Research, 53(6), 1478-1495.

Karrass, J., Walden, T. A., Conture, E. G., Graham, C. G., Arnold, H. S., Hartfield, K. N., et al. (2006). Relation of emotional reactivity and regulation to childhood stuttering. Journal of Communication Disorders, 39(6), 402-423.

Kim, J. H., Cho, S. M., Hong, C. H.. \& Hwang, S. T. (2006). The Korean Personality Rating Scale for Children (KPRC). Daegu: Korea Psychology Co., LTD.

Kim, Y. T., Sung, T. J. \& Lee, Y. K. (2003). Preschool Receptive-Expressive Language Scale (PRES). Seoul: Seoul Community Rehabilitation Center.

Kim, W. J., Lee, S, B., \& Sim, H. S. (2014). Anxiety and communication attitude in school-aged children who stutter. Special Education Research, $13,147-166$

Ko, Y. O. \& Kwon, D. H. (2010). The characteristics of anxiety and attitude based on severity of stuttering. Journal of Speech and Hearing Disorders, 19(1), 99-118.

Lee, J. S., Sim, H. S., \& Lee, S. B. (2013). Communication attitude in 3- to 5- year- old children who do and do not stutter. Special Education Research, 12(3), 5-22.

Manning, W. H. (2010). Clinical Decision Making in Fluency Disorders. (3rd ed.). Clifton Park, NY: Delmar Cengage Learning.

Miller, S. \& Watson, B. C. (1992). The relationship between communication attitude, anxiety, and depression in stutterers and nonstutterers. Journal of Speech and Hearing Research, 35(4), 789-798.

Min, B. B., Oh, H. S., \& Lee, J. Y. (2007). Temperament and Character Inventory Manual. Seoul: Maumsarang Co., Ltd.

Park, Y. S. (2015). Temperamental Characteristics of Preschool Children who Do and Do Not Stutter. Seoul: Ewha Womans University.

Riley, G. \& Riley, J. G. (2000). A revised component model for diagnosing and treating children who stutter. Contemporary Issues in Communication Sciences and Disorders, 27, 188-199.

Rothbart, M. K. \& Derryberry, D. (1981). Development of Individual Difference in Temperament. In Lamb, M. E., \& Brown, A. L. Advances in Developmental Psychology. Hillsdale, NJ: Lawrence Erlbaum Associates.

Sawilowsky, S. S. (2009). New effect size rules of thumb. Journal of Modern Applied Statistical Methods, 8(2), 597-599.

Schwenk, K. A., Conture, E. G., \& Walden, T. A. (2007). Reaction to background stimulation of preschool children who do and do not stutter. Journal of Communication Disorders, 40(2), 129-141.

Sim, H. S. (2000). A study on stereotypes of the Korean male adults who stutter. Communication Sciences and Disorders, 5(1), 1-17.

Sim, H. S., Shin, M. J., \& Lee, E. J. (2010). Paradise-Fluency Assessment-II. Seoul: Paradise Welfare Foundation.

Vanryckeghem, M., Brutten, G. J., \& Hernandez, L. M. (2005). A comparative investigation of the speech-associated attitude of preschool and kindergarten children who do and do not stutter. Journal of Fluency Disorders, 30(4), 307-318.

Weber, C. M. \& Smith, A. (1990). Autonomic correlates of stuttering and speech assessed in a range of experimental tasks. Journal of Speech and Hearing Research, 33(4), 690-706.

Woods, C. L. \& Williams, D. E. (1971). Speech clinicians' conceptions of boys and men who stutter. The Journal of Speech and Hearing Disorders, 36(2), 225-234

Yeom, H. K. (1998). (The) study of Preschool Children's Daily Stress Scale development and its validity (Unpublished master's thesis). Ewha Womans University, Seoul. 